\title{
Epstein-Barr virus facilitates the malignant potential of immortalized epithelial cells: from latent genome to viral production and maintenance
}

\author{
Jian-Hong Lu' ${ }^{1}$, Yun-Lian Tang ${ }^{1,3}$, Hai-Bo Yu ${ }^{1}$, Jian-Hua Zhou ${ }^{2}$, Chun-Yan Fu ${ }^{2}$, Xi Zeng ${ }^{1}$, Zheng-Yuan Yu ${ }^{1}$, Hong-Ling \\ $\mathrm{Yin}^{2}$, Ming-Hua Wu${ }^{1}$, Jun-Yi Zhang ${ }^{1,4}$, Xiao-Ling $\mathrm{Li}^{1}$ and Gui-Yuan $\mathrm{Li}^{1}{ }^{1, *}$
}

Epstein-Barr virus (EBV) is closely associated with several malignancies, including nasopharyngeal carcinoma. To investigate the EBV activity in tumor development, we tried to establish a malignant model of EBV-infected cells in nude mice. On the basis of the Maxi-EBV system, a human embryonic kidney epithelial cell line (293) with a low malignant potential was used for a stable EBV genome infection. The derived cell line, termed 293-EBV, exhibited obvious morphological transformation and significantly increased growth ability, with the cell cycle redistributed. The clonability and tumorigenicity were also substantially accelerated. In $293-E B V$ cells, the expression level of the transcription factor NF- $\kappa$ B and JNK2 were upregulated. The result suggested that latent membrane protein 1 (LMP1) was an important viral protein responsible for the enhanced malignant potential. Matured and budding virus particles were observed in tumor tissues, confirming the spontaneous reactivation of EBV from latent genome to lytic cycle at the site of tumor development. Primary culture of tumor tissues showed two patterns about the EBV maintenance or not in newly grown cells, and this was dependent on the thickness of the planted tissues. Moreover, the tumor cells lost EBV genome easily when subcultured at low density. Our findings revealed the cell-to-cell contact mechanism, which was required for the EBV maintenance in the tumor cells during the expansion of EBV-infected cells. This mechanism might give an explanation to the phenomenon that EBV genome in epithelial tumor cells becomes easily lost during subculture in vitro. Our results provided further evidence of a function for EBV in the etiology of tumor development.

Laboratory Investigation (2010) 90, 196-209; doi:10.1038/labinvest.2009.130; published online 7 December 2009

KEYWORDS: Epstein-Barr virus; latent infection; lytic cycle; malignancy; viral maintenance

Epstein-Barr virus (EBV) is a ubiquitous human gammaherpesvirus that is carried by a majority of human population as a lifelong latent infection. ${ }^{1}$ EBV is also known to be closely associated with several malignancies, including Burkitt's lymphomas and nasopharyngeal carcinoma (NPC). ${ }^{2,3}$ The latter is a prevalent cancer in southern China and Southeast Asia. EBV that contains a large-sized genome of about $170 \mathrm{~kb}$ has two phases in its life cycle: latent and lytic stages. ${ }^{4}$ During EBV latency, the copy number of viral DNA is maintained at a low level, with only a few genes expressed, and no virion is produced, whereas a mass of lytic genes occurs following reactivation of the lytic cycle and production of virus particles. ${ }^{4,5}$ The majority of EBV infection in vivo is latent. Almost all NPC cells contain EBV genome and express viral latent proteins such as latent membrane protein 1 (LMP1) and Epstein-Barr nuclear antigen 1 (EBNA1). ${ }^{6,7}$ LMP1 is an EBV oncoprotein that triggers multiple cell signaling events. ${ }^{1,4,8}$

Because of the cancer association and particular life cycle, EBV becomes one of the most complex viruses. The interaction between this virus and epithelial cells has long been of special interest because of EBV's close association with NPC. However, the transformation and malignancy capacity of EBV is based largely on evidence from B lymphocyte. ${ }^{1,6,9,10}$ In epithelial cells, the mechanism of EBV pathogenesis is not well understood, as the availability of in vitro infection and transformation model has been quite limited. ${ }^{11}$ Lack of malignant model of EBV stably infected epithelial cells has

\footnotetext{
${ }^{1}$ Cancer Research Institute, Xiangya School of Medicine, Central South University, Hunan, China; ${ }^{2}$ Department of Pathology, Xiangya School of Medicine, Central South University, Hunan, China; ${ }^{3}$ Cancer Research Institute, University of South China, Hunan, China and ${ }^{4}$ ENT Department, Xiangya Hospital, Central South University, Hunan, China

*Correspondence: Dr G-Y Li, MD, Cancer Research Institute, Xiangya School of Medicine, Central South University, Xiangya Road 110\#, Changsha, Hunan 410078, China. E-mail: ligy@xysm.net
}

Received 22 December 2008; revised 21 September 2009; accepted 25 September 2009 
especially been a problem for the investigation. ${ }^{12}$ Recently, EBV infected or growth-transformed epithelial cell lines have been established by using recombinant EBV expressing screening markers. ${ }^{13,14}$ However, the studies showed that EBV could not stably exist in human epithelial cells during passages. ${ }^{14,15}$ It seems that some factors such as epithelial cell environment go against EBV maintenance in the cell in vitro. Nevertheless, EBV has not been detected in normal epithelial cells or those adjacent to NPC, and the only examples of latent infection are those of carcinomas associated. ${ }^{16,17}$ This fact indicates that EBV is able to stably exist in epithelial tumor cells in vivo, and the occurrence of a latent infection is a substantial contributing factor to the development of carcinoma. Such situations prompt us to exploit a malignant model for investigating EBV infection and activity in epithelial cells.

On the basis of single gene genetics analysis, some EBV genes have been well documented, providing the clue for us to understand their functions in vivo. ${ }^{1,18}$ Studies have shown that multiple viral genes may be involved in the pathogenesis of EBV-associated tumors. ${ }^{8,19,20}$ Therefore, further and comprehensive understanding may require studies in the context of the whole virus genome. ${ }^{21}$ On the basis of MaxiEBV system, it is now feasible to study EBV and its functions in the whole genome. ${ }^{1,21,22}$ This system contains the complete EBV genome cloned onto a mini-F plasmid that carries selection markers in eukaryotic and Escherichia coli, as well as expression cassette for green fluorescent protein (GFP), which makes it convenient for the virus readout. By using this system, the EBV genome is able to be transfected into cells independent of entry through CD21, which is the EBV membrane receptor on human B-lymphocytes. ${ }^{23}$ Earlier studies have implicated that it is difficult for non-tumorigenic epithelial cells with EBV-only infection to trigger the malignancy in nude mice. ${ }^{13-15}$ In this study, for EBV genome transfection, we used a human embryonic kidney epithelial cell line (293) with a low malignant potential. The results highlighted the importance of EBV genome and its interaction with the cellular environment during the tumor development.

\section{MATERIALS AND METHODS Cell Line and Plasmids}

The human embryonic kidney epithelial cell line (293, ATCC origin) was preserved and propagated in our laboratory (Cancer Research Institute, Central South University). The cells were grown in Dulbecco's modified Eagle's medium (DMEM, Sigma) complemented with $10 \%$ fetal calf serum. The plasmid p2089 (Maxi-EBV) containing the complete EBV genome of B95-8 strain was kindly provided by Professor Dr W Hammerschmidt. ${ }^{22}$

\section{Antibodies and Nude Mice}

The LMP1 and EBNA1 proteins were detected with monoclonal antibodies produced by Dako Cytomation (USA) and
Abcam (UK), respectively. For detection of proteins of cellular signal pathways, rabbit anti-c-Jun, c-Fos, JNK2 and mouse-anti-p53 (wild type), NF- $\kappa \mathrm{B}(\mathrm{p} 65)$ were used. These antibodies were produced by Santa Cruz Biotechnology Inc. (USA). In immunofluorescence detection, the mouse monoclonal antibody to E-cadherin and rabbit to mouse IgG-H (Rhodamine) were produced by Abcam. SPF Balb/c nude mice of 4 weeks old were purchased from SLAC Laboratory Animal Co. Ltd (Shanghai, China). All animals were bred and maintained under strict sterilized environmental conditions.

\section{Generation of the Cell Line Stably Transfected by the EBV Genome}

The plasmid p2089 contained a mini-F factor, and carried expression cassettes for EGFP and selection markers, hygromycin (hyg) phosphotransferase for selection in eukaryotic cells and chloramphenicol acetyltransferase for selection in E. coli. ${ }^{22}$ The plasmid was transfected into 293 cells, and hyg ${ }^{\mathrm{r}}-$ EGFP-EBV stably transfected cells, including single clones and pool clones, were screened according to the protocols. ${ }^{22,24}$ The pool clones containing at least 30 single clones from different wells were collected and mixed. The cell line from pool clones, designated 293-EBV, were amplified and used in this study. The 293-EBV cell line was then confirmed to support lytic cycle of EBV induced by the viral genes BZLF1 and BALF4 expressed from two plasmids transiently transfected into the cells as described. ${ }^{24}$ The supernatants were used to infect B-cell line (Raji), 293 and the immortalized nasopharyngeal epithelial cell line (NP69). ${ }^{25}$ GFP positive (GFP + ) Raji cells were then determined by flow cytometry, allowing direct assessment of infectious EBVs' generation.

\section{Cell Proliferation Assay}

Cell proliferation was measured by two experiments, MTT and mitotic index analyses. For MTT analysis, the cells were cultured in 96-well plates at a density of $3 \times 10^{3}$ cells/well in $200 \mu \mathrm{l}$ of medium for $1,2,3,4,5$, and 6 days, respectively. The cells were incubated with $20 \mu \mathrm{l} \mathrm{of} 5 \mathrm{mg} / \mathrm{ml}$ MTT (tetrazoliumsalt 3-[4,5-dimethylthiazole-2-yl]-2,5-diphenyltetrazolium bromide) in complete medium for $4 \mathrm{~h}$, and then were dissolved in dimethyl sulfoxide. Absorbance at $490 \mathrm{~mm}$ was measured by using an enzyme-linked immunosorbent assay plate reader (Sunrise remote, Tecan Austria $\mathrm{GmbH}$ ). For the determination of cell mitotic index, $4.8 \times 10^{4}$ cells were seeded onto a poly-Lysine-treated coverslip each in one well of a six-well plate. From the first to seventh day, the coverslips were washed slightly with PBS, fixed with formalin, stained with Giemsa, and then the mitotic cells in 1000 cells were counted manually. Each experiment was repeated for three times independently.

\section{Cell Cycle Analysis}

Cell cultures were plated in $10-\mathrm{cm}$ dishes at $50 \%$ confluence and allowed to grow exponentially. The adherent cells were 
collected by trypsinization, pooled with the non-adherent cells, and washed with PBS before being fixed in $70 \%$ cold ethanol overnight at $4^{\circ} \mathrm{C}$. For the analysis, the cells were adjusted to a final density of $1 \times 10^{6}$ cells $/ \mathrm{ml}$ in PBS-containing RNase $(1 \mu \mathrm{g} / \mathrm{ml})$ and stained with $10 \mu \mathrm{g} / \mathrm{ml}$ propidium iodide (Roche Diagnostics, Switzerland) for $30 \mathrm{~min}$ at room temperature. The multiparameter analysis of $10^{5}$ cells was performed on FACScan Flow Cytometer using CellQuest software (BD Biosciences, San Jose, CA, USA). The experiment was repeated thrice.

\section{Colony Formation in Soft Agar}

To evaluate the ability of individual cell lines to grow in an anchorage-independent manner, cells were plated in soft agar. In brief, a bottom layer was prepared using $3 \mathrm{ml}$ of culture medium containing $0.5 \%$ agar and $10 \%$ fetal bovine serum, and then was placed in six-well plates and allowed to solidify. Cells were suspended in $50 \mu \mathrm{l}$ of completed DMEM. Culture medium $(2 \mathrm{ml})$ containing $0.3 \%$ agar was added to the cell suspension before seeding on the plates. The plates were examined twice per week till 30 days. The colonies were counted manually after 3 weeks. The experiment was repeated three times.

\section{Tumor Formation in Nude Mice}

Cells $\left(2 \times 10^{6}\right.$ or $\left.4 \times 10^{6}\right)$ in $0.2 \mathrm{ml}$ growth medium were subcutaneously injected into $\mathrm{BALB} / \mathrm{c}$ nude mice aged 4 weeks. The mice were monitored for the appearance and growth rate of tumors, and killed after 8 weeks. Cell growth medium and cell lysates with the same cell number primarily were used for negative control. The mice bearing tumors were detected fluorescence under the Animal Fluorescence Imaging System (Photometrics, USA). For histological examination and EBV detection, tumor tissues were dissected, fixed in $10 \%$ buffered formaldehyde, and embedded in paraffin. The fresh tissue specimens were observed for virus under a transmission electron microscopy ( $\mathrm{H}-7500$, Japan). To ensure the transcription of EBV genes, total RNA was extracted from the tumor tissue and the EBV-encoded LMP1 gene, including the whole ORF (about $1350 \mathrm{bp}$ ), was amplified by RT-PCR.

\section{Western Blot and Southern Blot Analysis}

Cells were harvested at 90\% confluence and lysed. Cell extracts containing $50 \mu \mathrm{g}$ of proteins were separated in 8-12\% SDS-PAGE gels and electroblotted onto nitrocellulose membranes (Hyclone Laboratories, Logan, UT, USA). The membranes were blocked using Tris-buffered saline $(25 \mathrm{mM}$ Tris- $\mathrm{HCl}, 150 \mathrm{mM} \mathrm{NaCl}, \mathrm{pH} 7.5$, and $0.05 \%$ Tween 20), containing $5 \%$ non-fat milk followed by overnight incubation with primary antibodies at $4^{\circ} \mathrm{C}$. After three washes, antihorseradish peroxidase antibodies were added. The anti$\beta$-actin antibody (Santa Cruz) was used as a loading control. For EBV genome DNA detection by Southern blot, cell gDNA were extracted using an easy nucleic acid isolation kit
(Omega bio-tek, USA). Cellular DNA $(10 \mu \mathrm{g})$ was digested with the restriction enzyme BamHI and separated by electrophoresis in $0.8 \%$ agarose gel, followed by transfer to positively nylon membrane (GE Healthcare, UK). The previously established plasmid BALF4/pcDNA3. ${ }^{24}$ was digested with BamHI and EcoRI, and the BALF4 segment was obtained for probe labeling. The probe labeling and blot detection were performed according to the instructions of a DIG high prime DNA labeling and detection starter kit (II) (Roche, Germany). Chemiluminescence analysis was performed under the Multil-imager system (Alpha Innotech Corp., USA).

\section{In Situ Hybridization for EBV Detection}

Oligonucleotide probe of EBER1 was digoxigenin-labeled at the $3^{\prime}$-terminal. Tumor specimens were formalin-fixed, paraffin-embedded, and sectioned. Fresh cell specimens were seeded onto coverslips. Tumor tissues were seeded and cultured for 11 days and the fresh cells were cultured for $30 \mathrm{~h}$. The cells were then washed three times gently, fixed for $10 \mathrm{~min}$ in 10\% PBS-buffered formaldehyde. EBV detection was performed by using an enhanced sensitive in situ hybridization (ISH) detection kit (Boster Inc., Wuhan, China) according to the manufacture's instructions.

\section{Immunofluorescence}

Immunofluorescence was performed for the detection of epithelial adherens junction protein E-cadherin. Fresh cell specimens were obtained as described above in ISH detection. The cells were treated with $0.25 \%$ triton X-100 for $10 \mathrm{~min}$ and washed with PBS, then the mouse monoclonal antibody to E-cadherin (1:50), which had species reactivity (it reacts with human, not with mouse and rabbit), was used and incubated overnight at $4{ }^{\circ} \mathrm{C}$. After three washes with PBS, the coveslips were incubated with rabbit polyclonal antibody to mouse (Rodamine labeled) (1:600) for $2 \mathrm{~h}$ at room temperature and washed three times. Then they were treated with Hoechst (Beyotime Inc., Shanghai, China) for $5 \mathrm{~min}$ and washed.

\section{Primary Culture of the Tumor Tissues and Subculture of the Tumor Cells}

Tumor tissues were taken from the nude mice under aseptic conditions, and rinsed for several minutes with D-Hank's solution. After being chopped finely, the tissues were put onto the bottom of culture coverslips or flasks in a small volume of growth medium, then the medium was refreshed every 1-2 days. After 10-13 days of culture in flask, the tissue and newly grown cells were trypsinized together, the cells (passage 1) were then subcultured. From the third passage, the cells were used for a comparison at different density levels. For high confluence culture, the cells of each passage were transferred at 1:2 ratios after becoming fully confluent, and for low confluence culture, the ratio was 1:10 (from 3 to 13 passages) or 1:20 (from passage 13 to 14 ). For each pas- 
a
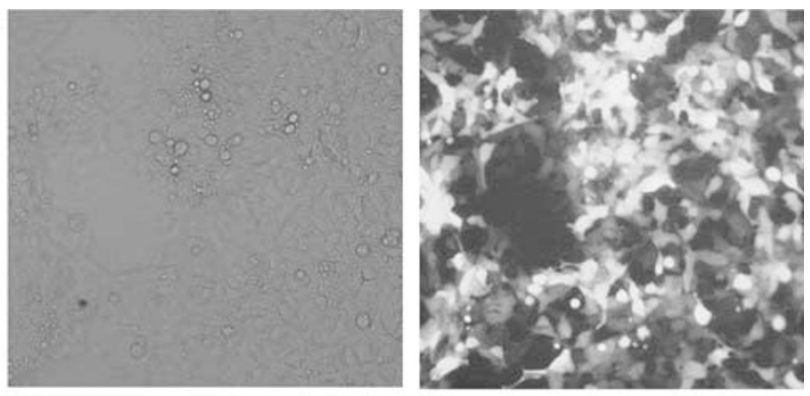

b 293-EBV

293

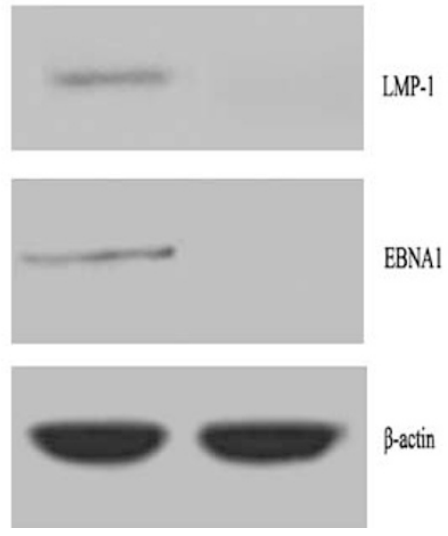

sage, the cells were allowed to grow to full confluence in the same size flask $(50 \mathrm{ml})$, and then they were used for the next passage.

\section{Subline Isolation of the Tumor Cells and Their Identification}

Cells from the primary culture of passage 5 were seeded in sixwell plates, each well containing 200 cells. After 24-30 days, the colonies with or without EGFP expressions (EGFP $+/-$ ) were selected separately for amplification. To ensure each clone or cell line was derived from the 293 cells, the E1A gene of adenovirus $C$ serotype 5 was amplified from cell gDNA by PCR. The primers were designed according to the sequence in GenBank (accession number, AY339865), producing an expected amplicon of $770 \mathrm{bp}$. The full-length LMP1 gene was also amplified from the cellular gDNA using about $0.2 \mu \mathrm{g}$ in $1 \mu \mathrm{l}$ input DNA. To identify the species of the cells from human or mouse, a mutiplex PCR-based assay was performed

Figure 1 The derived cell line stably transfected with EBV genome (MaxiEBV). (a) The cell line 293-EBV showed EGFP expression under an inverted fluorescence microscopy (right panel). The left panel showed the phase contrast of the same field as in the right. (b) Western blot showed that the 293-EBV cells expressed EBV latent proteins, EBNA1 and LMP1. a

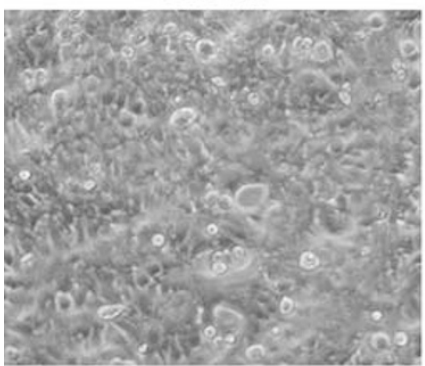

293
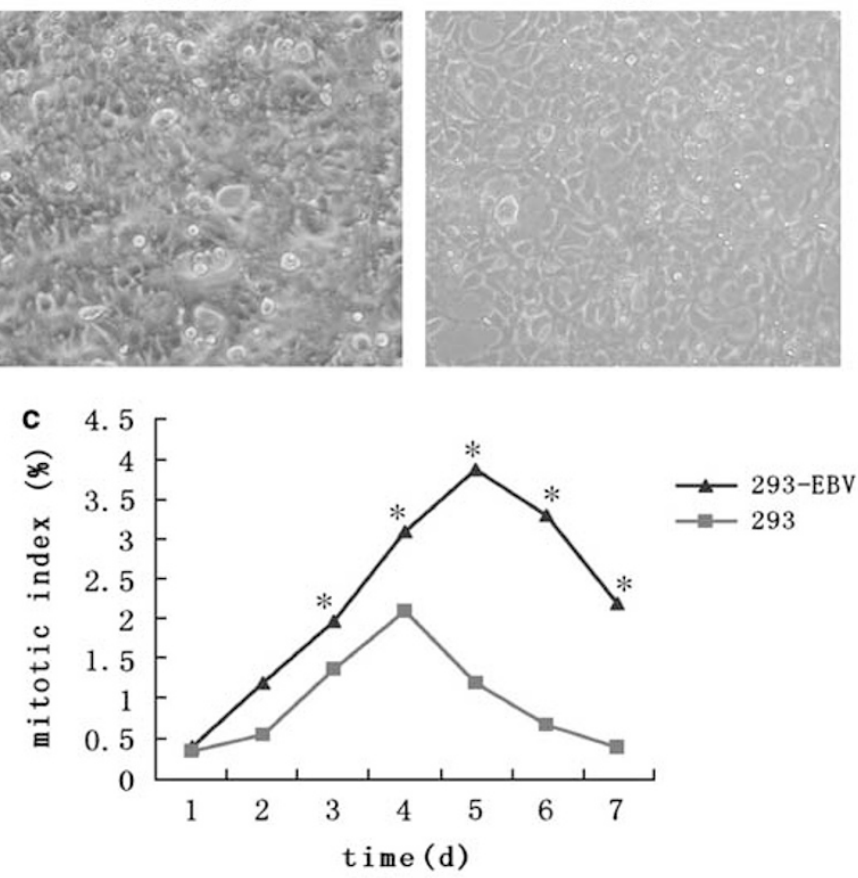

b
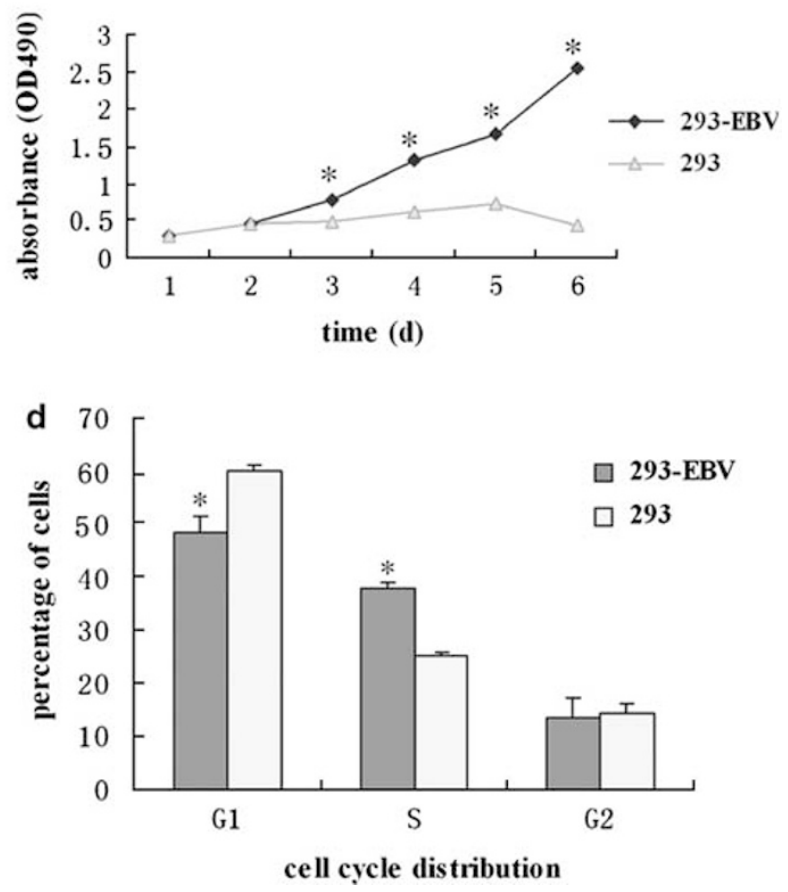

Figure 2 Effect of EBV on the growth ability of the 293 cells. (a) Morphology of the cell lines in culture. The 293-EBV cells became partly multilayered and formed foci after reaching confluence. (b) Growth curve assayed by MTT analysis. ${ }^{*}$ From days 3-6, the 293-EBV cell line showed increased growth ability significantly when compared with 293 cells $(P<0.01)$. (c) Cell mitotic index assay. ${ }^{*}$ From days $3-7$, the 293-EBV cell line showed significant elevated proliferation $(P<0.01)$. (d) Alterations in cell cycle distribution of EBV-infected cells. ${ }^{*}$ The $\mathrm{G} 1$ and $\mathrm{S}$ phase of 293 -EBV cells showed significant difference when compared with that of the 293 cells $(P<0.05)$. For $(\mathbf{b}-\mathbf{d})$, the data corresponded to the mean values of three independent experiments. 
as described. ${ }^{26}$ This new method generates size-specific amplicons by targeting the mitochondrial genome, capable of detecting a contamination of $1 \%$ cells. For human species, the amplicon size is $391 \mathrm{bp}$, and it is $150 \mathrm{bp}$ for that of mouse species. All the cell sublines were assayed within 10 passages.

\section{RESULTS}

\section{Establishment of the Cell Line Stably Transfected with EBV Genome}

After 3-4 weeks of selection with hyg in the culture medium of the 293 cells, a derived cell line, termed 293-EBV, from pool clones stably transfected with p2089 was generated. Similar to earlier results, ${ }^{25}$ the cell line expressed EGFP in $>98 \%$ of cells by FACS analysis, and was confirmed to support lytic cycle of EBV. In normal culture and passage, the 293-EBV cells were grown in complete medium without application of hyg selection. The supernatant of the cells induced by lytic cycle was able to infect Raji cells with a positive ratio of about $28-30 \%$ determined by flow cytometry, whereas it failed to infect the 293 or NP69 epithelial cells. The cell line 293-EBV expressed EBV latent proteins, EBNA1 and LMP1 (Figure 1b), similar to that in NPC that exhibits a type II EBV latency pattern. ${ }^{18}$ The attributes of stable expression of EBV latent proteins with the ability to induce an active lytic cycle in the cell line showed that it was an adequate model system of latent EBV infection. Prior to special experiments such as proliferation and transformation assays, to ensure all cells being EGFP +, the cells might be treated with hyg once for 2-3 days.

\section{Effects of EBV Genome Infection on the Growth, Biologic Properties, and Signal Pathways of the Cells}

The cell line 293-EBV became partly multilayered and formed foci after they reached full confluence (Figure 2a), whereas the 293 cells only grew till becoming a monolayer, not exhibiting this kind of morphological transformation. Compared with the 293 cells, the 293-EBV showed enhanced proliferation abilities in MTT and mitotic index assays (Figure $2 \mathrm{~b}$ and $\mathrm{c}$ ), demonstrating that the EBV genome facilitated the cell growth and proliferation. Cell cycle analysis showed that the EBV-infected cells altered the cell cycle distribution, with the percentage of G1 phase cells significantly downregulated, and that of $S$ phase increased (Figure 2d).

Earlier gene expression analysis has shown that EBV-LMP1 activates several distinct signal transduction pathways such as the nuclear factor NF- $\kappa \mathrm{B}$ and activator protein 1 (AP-1). ${ }^{1,27-29}$ Activation of NF- $\kappa$ B is especially important for the increased proliferation of tumor cells. Rel A (p65) is the major component of NF- $\kappa$ B activated by LMP1. AP- 1 is a dimeric complex that comprises members of the JUN (such as c-JUN) and FOS (such as c-FOS). ${ }^{30}$ JNKs are c-JUN $\mathrm{N}$-terminal kinases. ${ }^{31}$ In this study, the effect of EBV infection on these two pathways and the tumor suppressor p53 were detected. As shown in Figure 3, the expressions of $\mathrm{NF}-\kappa \mathrm{B}$ and JNK2 were effectively upregulated. For the AP-1

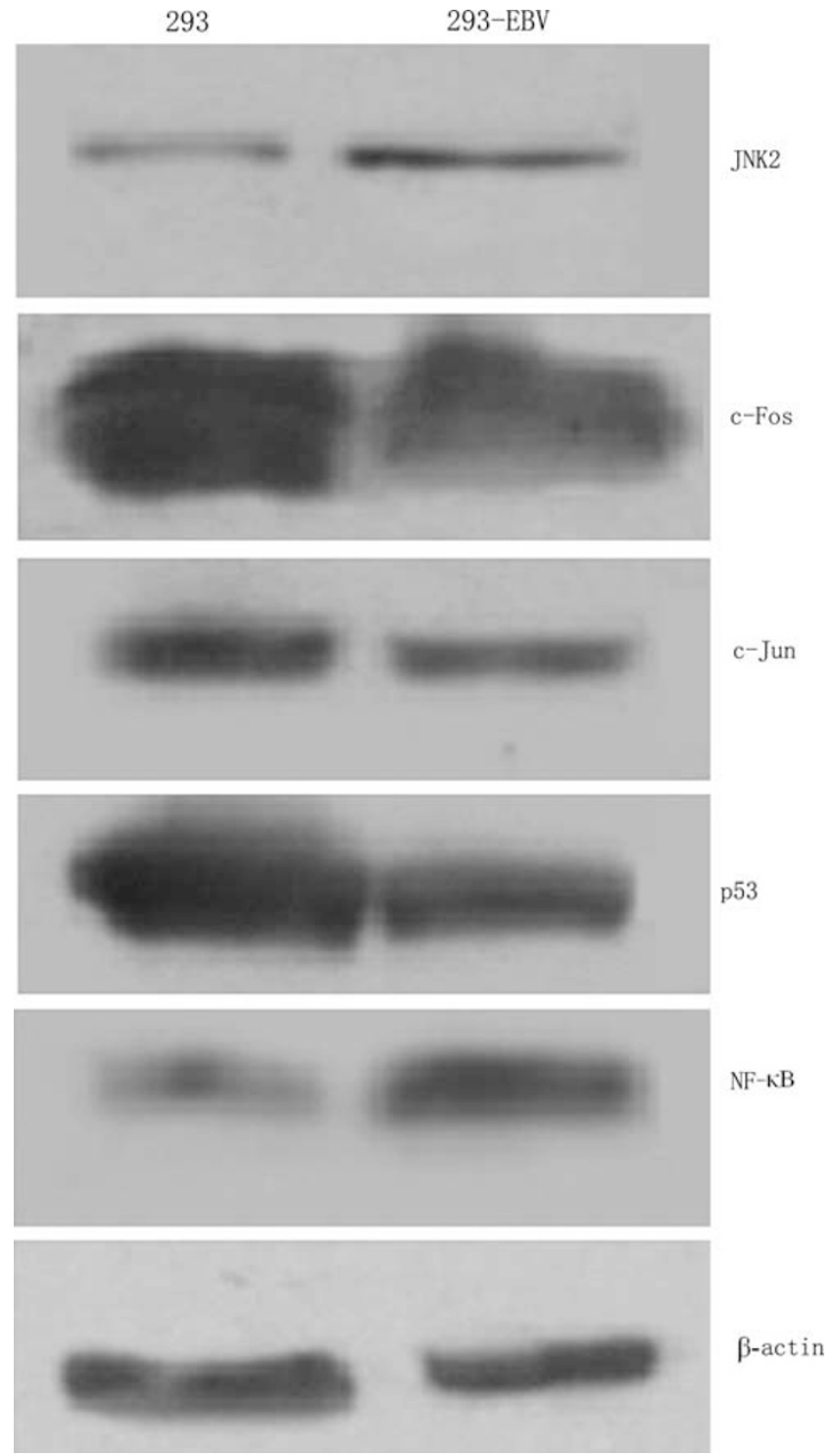

Figure 3 Effect of EBV on the cellular signal pathways. In 293-EBV, the expression of the transcription factor NF- $\kappa$ B (p65) and the kinase JNK2 were upregulated. The expressions of c-Jun and c-Fos, which are the members of the activation protein (AP-1) pathway, were downregulated. The wild-type suppressor $\mathrm{p} 53$ was also downregulated.

pathway, c-Jun and c-Fos were downregulated. The expression of wild-type p53 was reduced in the 293-EBV cells.

\section{Alteration of Transformation Phenotype in the EBV- Infected Cell Line}

To explore the effect of EBV genome infection on the transformation phenotype of the cells, two types of experiments were designed. These experiments were colony formation in soft agar and tumor formation in nude mice. As shown in Figure 4, the 293-EBV cells formed more $(P<0.01)$ and larger colonies than that of 293 cells. The 293 cells did not form colonies containing $>40$ cells. When twofold of cells $\left(1.6 \times 10^{5}\right)$ were used, more than doubled (data not 

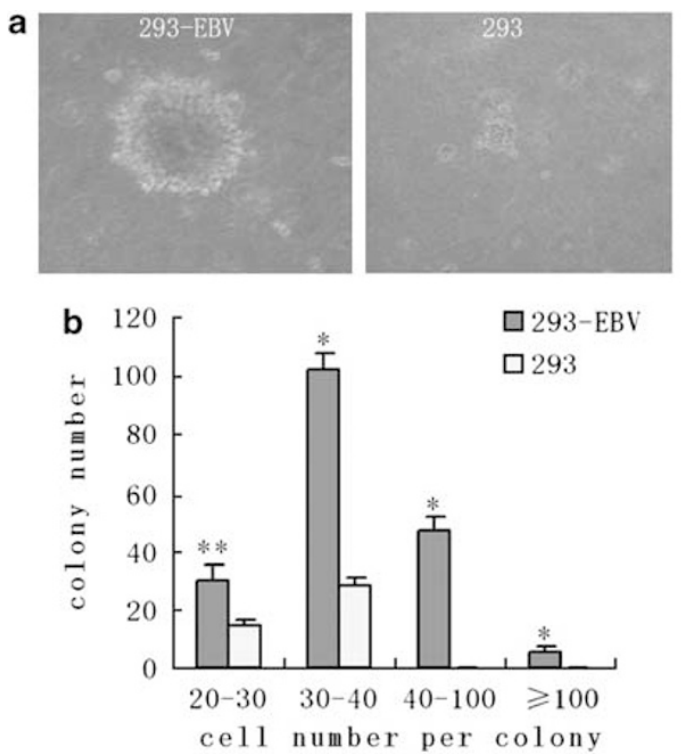
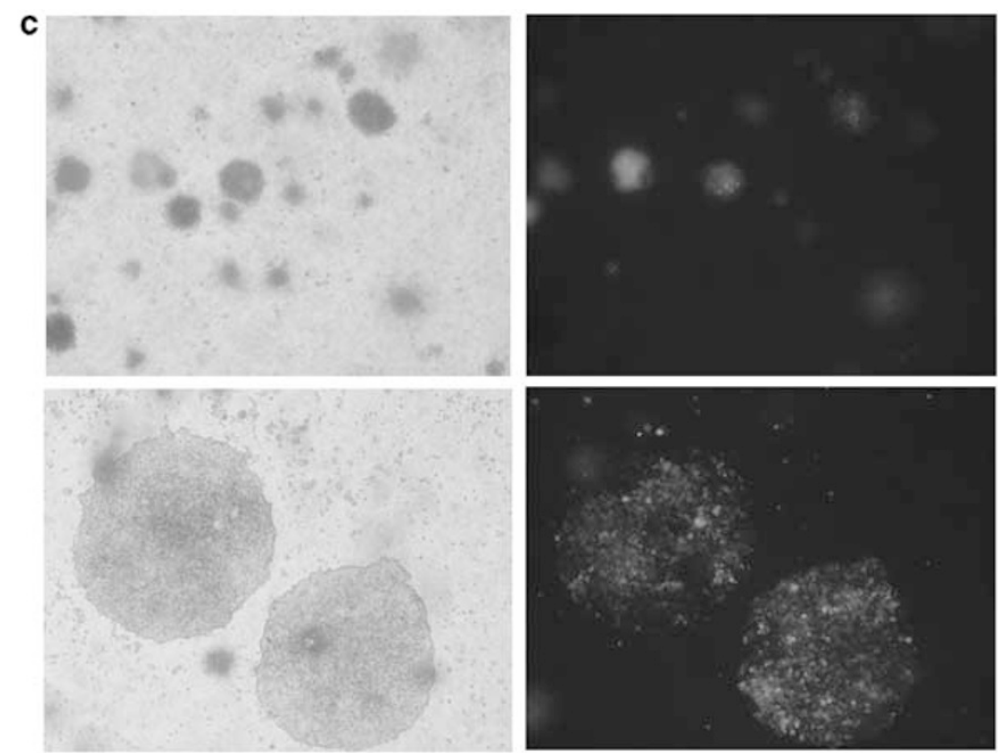

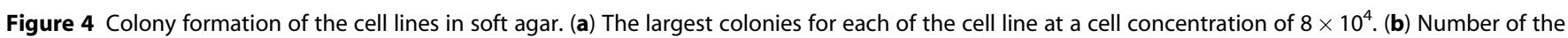
colonies formed by each cell line. The colonies were counted manually according to the range of the cell number in them. ${ }^{\star \star} P<0.05$, ${ }^{\star} P<0.01$ for the 293 EBV cells compared with the 293 cells. (c) When using a twofold of cells $\left(1.6 \times 10^{5}\right)$, the 293-EBV cells formed more (more than a twofold) and larger colonies, and all the colonies exhibited EGFP expression (left, phase contrast). All showed the results at 21 days. Original magnification: $\times 200$ (a), $\times 40$ (c).

shown) and larger colonies (Figure 4c) formed for the 293EBV cells, whereas there was no effect on the 293 cells. The colonies formed by the 293 cells did not grow any longer after 21 days, whereas colonies formed by the 293-EBV continued to grow and express EGFP until the last observation at day 30.

In the second type of experiment, the result showed that the 293-EBV cells formed tumors at the site of inoculation in nude mice (4/6, Figure 5a; Table 1), whereas the 293 cell line did not form any (Table 1$)$ at the same cell dose $\left(2 \times 10^{6} \%\right.$ mice). At doubled number of cells $\left(4 \times 10^{6} /\right.$ mice $)$, the 293 EBV cells formed tumors earlier and at a higher ratio (5/5, Table 1). The result also showed that more than a mean of tripled weight of tumors formed when twofold of cells were used, demonstrating dose dependence as shown in the colony detection. The 293 cells exhibited a low malignant potential in nude mice at the given cell number of $4 \times 10^{6} /$ mice $(1 / 5$ formed a tumor after 42 days; Figure $5 b$; Table 1). The tumor tissues were made into paraffin sections, and histopathological examination of hematoxylin-eosin staining showed all the tumor tissues derived from the cell lines with undifferentiated carcinoma (293-EBV) or poorly differentiated carcinoma (293) (Figure 5b).

\section{EBV Activity in Tumor Tissues}

Tumor samples in paraffin sections were undertaken EBER1 detection by ISH, which is the gold standard for EBV detection. The result showed that the EBV small RNA presented in all the nucleus of tumor cells from 293-EBV, with the exception of some small areas composed of a few cells (Figure 6a). In the detection under transmission electron microscopy, a number of pre-matured virus particles were observed in nucleus of the tumor cells from the 293-EBV cells (Figure 6bA). In some individual cells, matured virions were found in cytoplasm, and a budding virion was observed as indicated in Figure 6bB.

\section{EBV Maintenance or not in Tumor Cells during Primary Culture}

In primary culture of the tumor tissues, the cells grew in two clear-cut patterns by the thickness of the seeded tissues and whether the cells on the tissue rim was able to grow directly or not. For a relatively thick tissue piece, the newly grown cells usually had to be released to the out rim. For a cluster of tissue cells or the thin tissues, which might have been scattered onto the flask bottom during being seeded, they grew directly after adhering to the flask wall. Equally to the growing patterns, two patterns about EBV footprint in the cells were also observed. Outwards the thick tissue rim, the newly grown cells completely lost EGFP signal starting from the early released cells till they reached full confluence (Figure 7a). However, all the directly grown cells and their daughter cells sustained EGFP expression (Figure 7b). The loss of EGFP signal indicated a potential loss of EBV genome from the tumor cells, and the ISH detection confirmed it (Figure $7 \mathrm{c}$ and $\mathrm{d}$ ). In primary culture, the cells showed some changes in morphology with increased proportion of fibroblast-like cells growing at low density. They would grow back to normal morphology as that of the 293 when all of them were digested together and distributed homogeneously, being provided a normal culture condition. Immunofluorescence analysis of human E-cadherin showed that almost all the cells 

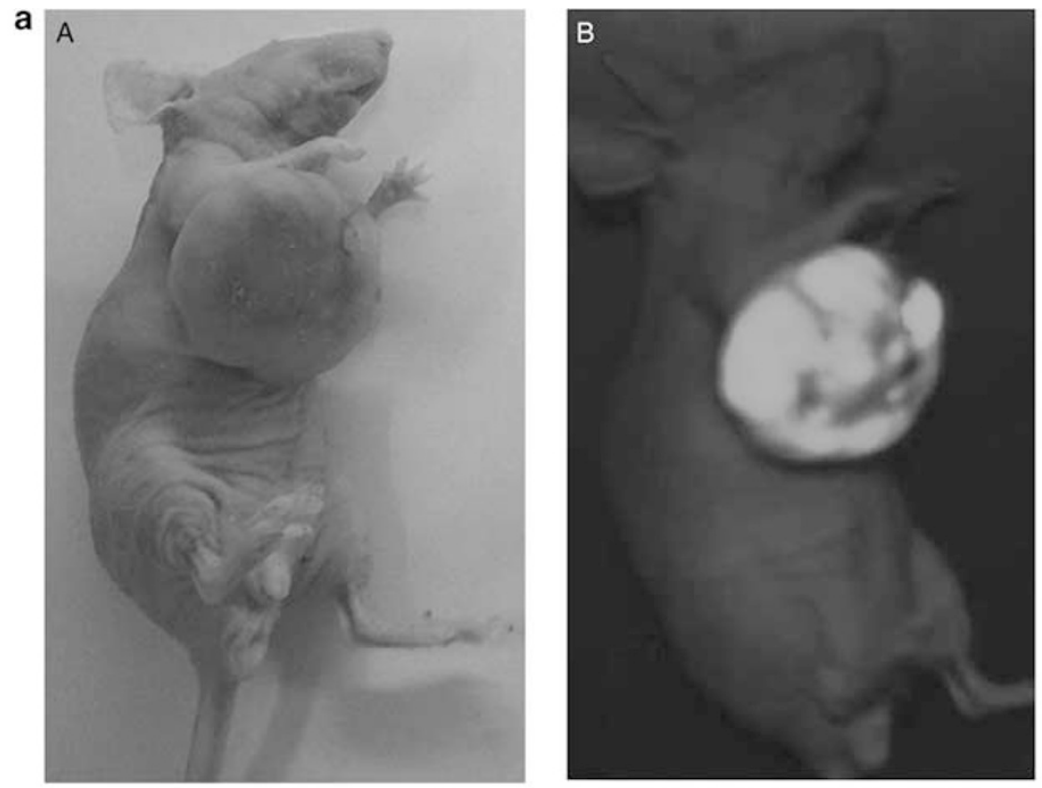

b

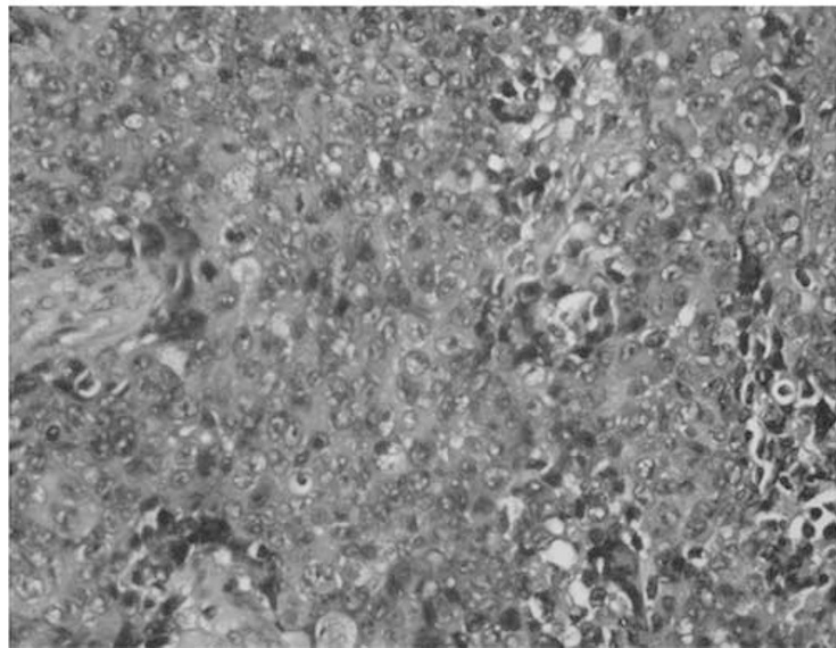

293-EBV

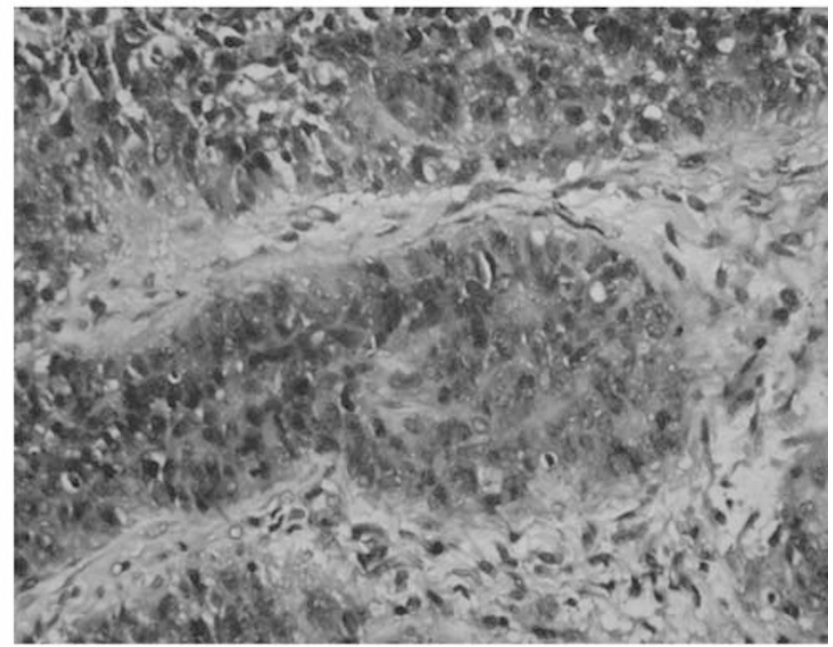

Figure 5 Tumor development of the cell lines in nude mice. (a) At the cell dose of $2 \times 10^{6} /$ mice, the 293 -EBV cells formed tumors at the site of inoculation in nude mice and the 293 cells did not. (A) One tumor formed by the 293-EBV cells. (B) The tumor (A) was detected fluorescence under the Animal Fluorescence Imaging System. (b) Histopathological examination of paraffin sections by hematoxylin-eosin staining, showing them with undifferentiated (293-EBV) or poorly differentiated (293) carcinomas. For the tissue from the 293 cells, the original tumor was formed at a higher dose $\left(4 \times 10^{6}\right.$ cells/mice). Original magnification: $\times 200$ (b).

Table 1 Tumor induction of the cell lines in nude mice

\begin{tabular}{|c|c|c|c|c|}
\hline Cell lines & Cell number per mice & Tumor frequency & Day of tumor first detected & Average weight of the tumors ( $\mathrm{g}$ ) \\
\hline 293-EBV & $2 \times 10^{6}$ & $4 / 6$ & 16 & 1.28 \\
\hline \multirow[t]{2}{*}{293} & $2 \times 10^{6}$ & $0 / 6$ & - & - \\
\hline & $4 \times 10^{6}$ & $1 / 5$ & 42 & 0.36 \\
\hline
\end{tabular}

Cells were injected subcutaneously. Tumors developed at the site of injection and were about $2 \mathrm{~mm}$ in diameter when first detected by palpation. 
a

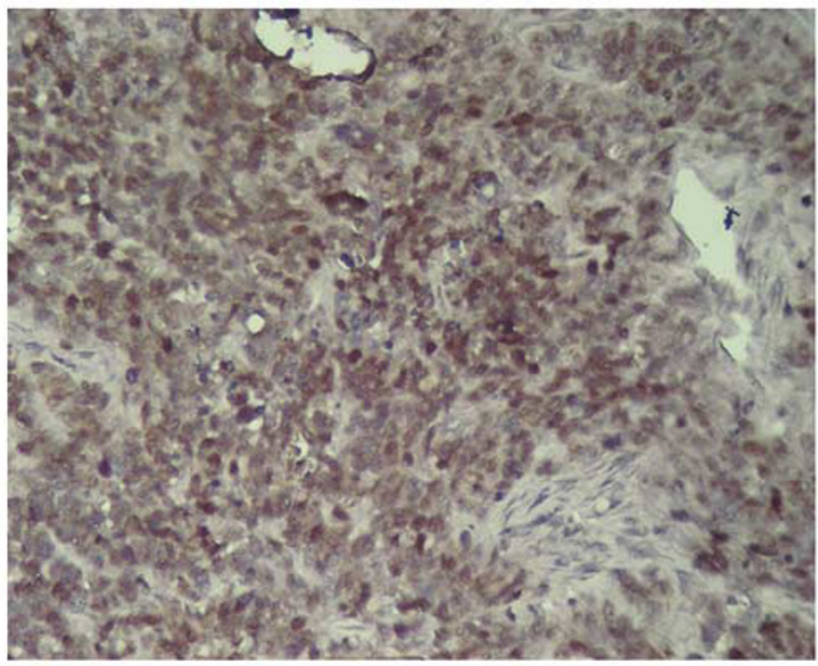

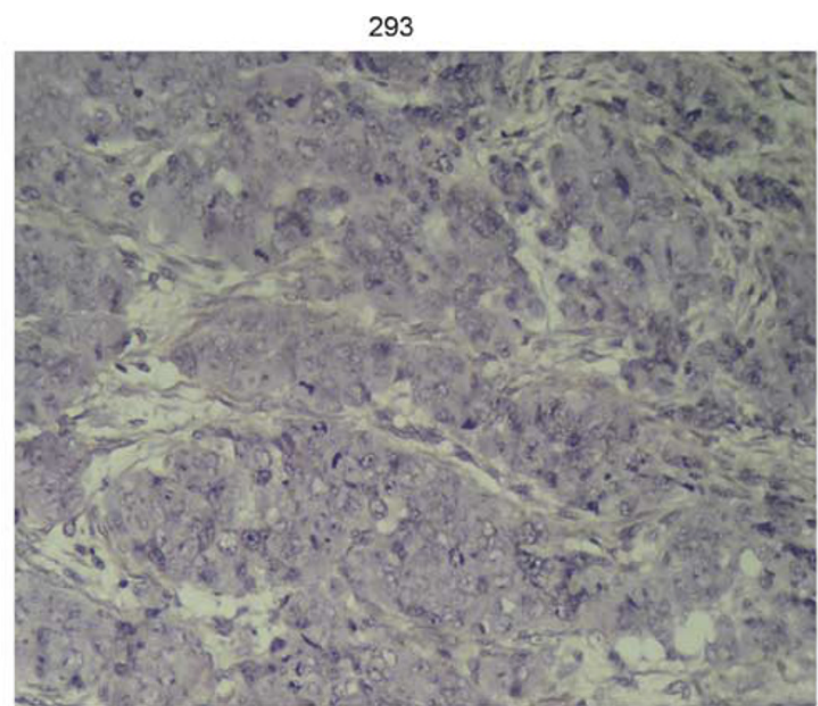

b
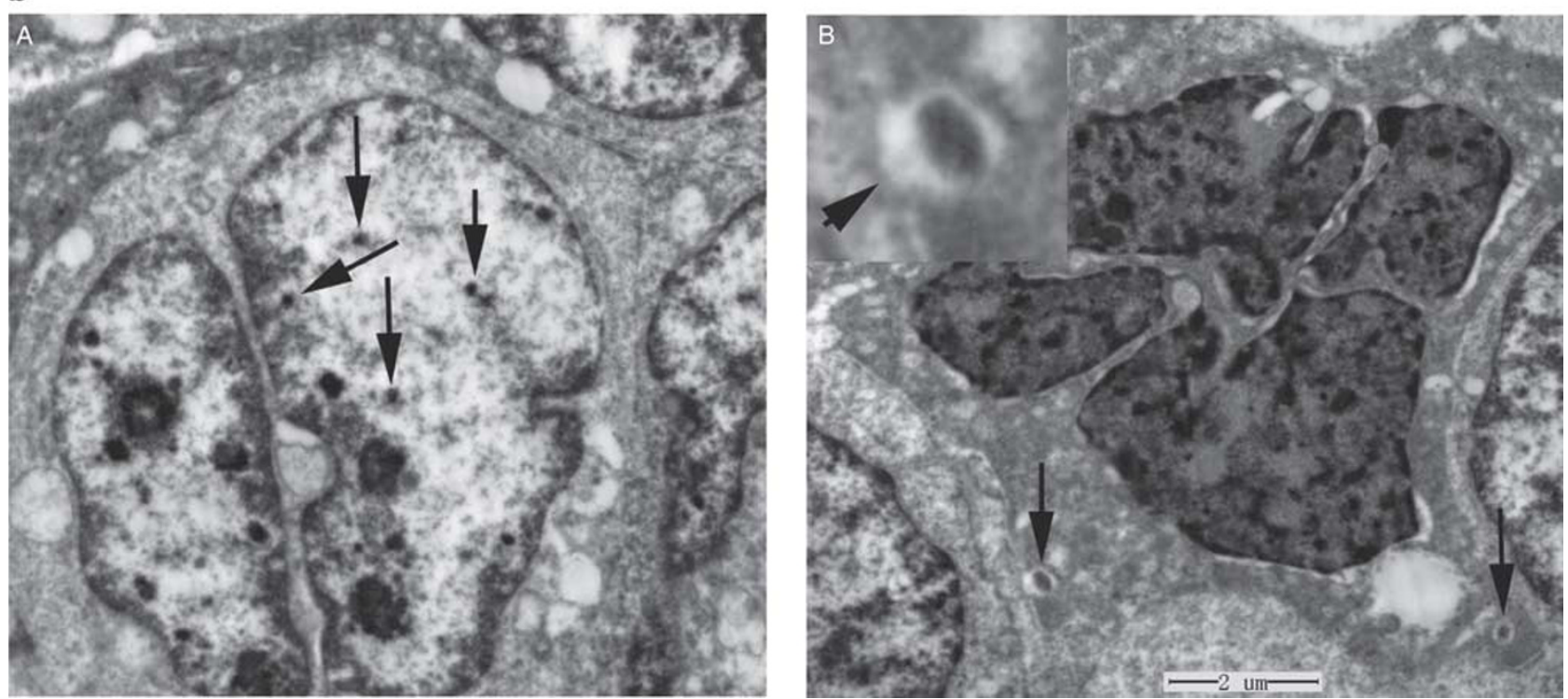

Figure 6 EBV detection in tumor tissues. (a) ISH detection of EBER1 in paraffin sections of tumor tissues. Almost all tumor cells (>95\%) from the 293-EBV indicated strong EBER1-positive staining in nucleus, and those from the 293 cells showed negative. (b) EBV observation under transmission electron microscope. (A) There are a number of pre-matured EBV particles in nucleus as indicated (arrows). (B) Typical herpesvirus-like particles were observed in cytoplasm of some cells. The left one at the site of the cell membrane was budding, with the magnified image being shown at the upper left corner (short arrow). Original magnification: $\times 200$ (a). Bar, $2 \mu \mathrm{m}$ (b).

from primary cells were human species (negative for no more than $1 \%$ cells that were probably mouse-origin) (Figure $8 \mathrm{a}$ and b). Further experiments by the multiplex PCR of cell species identification confirmed that these EGFP - cells were from human species, and contained the E1A gene as the 293 cells did, but no longer contained the EBV-LMP1 gene (Figure 9). To detect mouse species cells that might come from the mouse stromal cells, cells of different passage from several primary outgrowths were detected by multiplex PCR with a reduced primer annealing temperature (from 55 to $50^{\circ} \mathrm{C}$ ) for the purpose of increasing the reaction sensitivity, and the result showed that mouse-origin cells might possibly exist in the mixture cells at 1-3 passages, at most 5 passages.

\section{EBV Maintenance or not in Tumor Cells during Subculture}

The result of tissue primary culture suggested that the expansion of EBV + cells might probably need cell-to-cell contact, and then the density in subculture might have effect on the EBV + cell expansion. As shown in Figure 10b, when cultured at low density, the tumor cells lost EBV genome easily. Clustered cells exhibiting the loss of EBV readout was easily observed when cultured at low confluence 

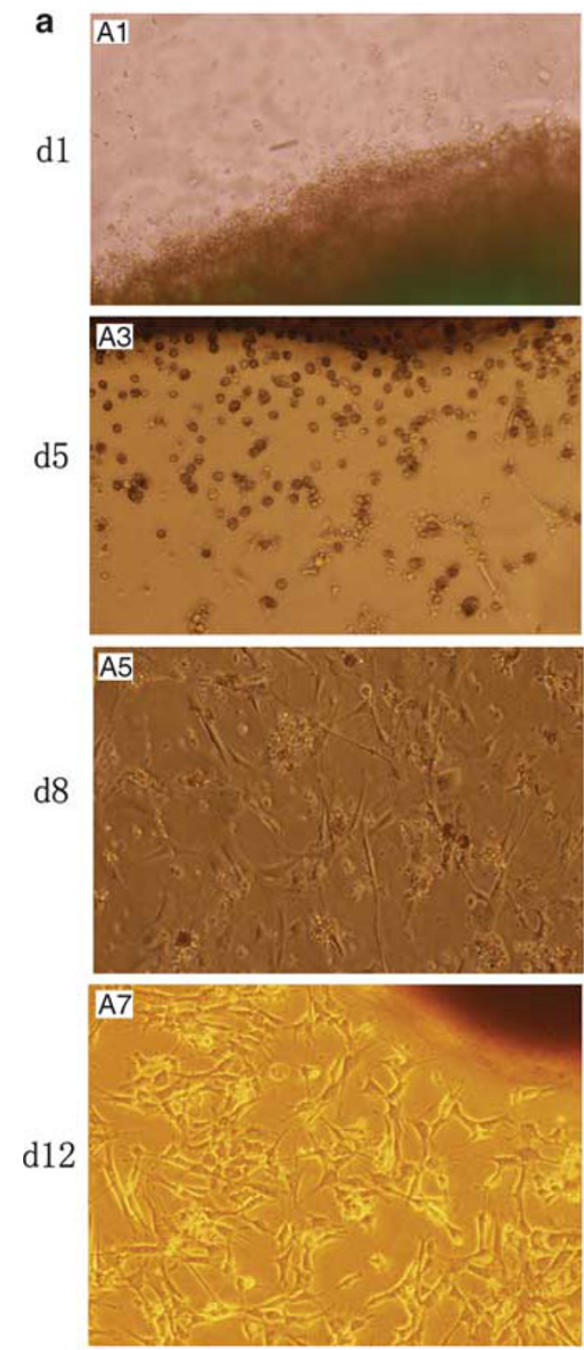

b
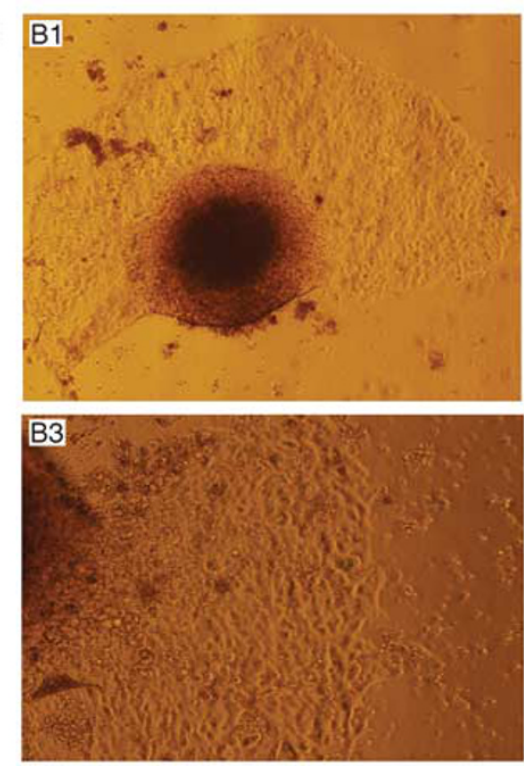
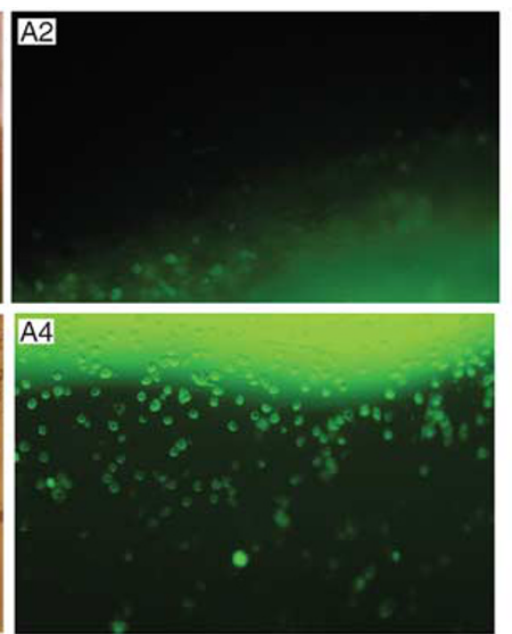

A6
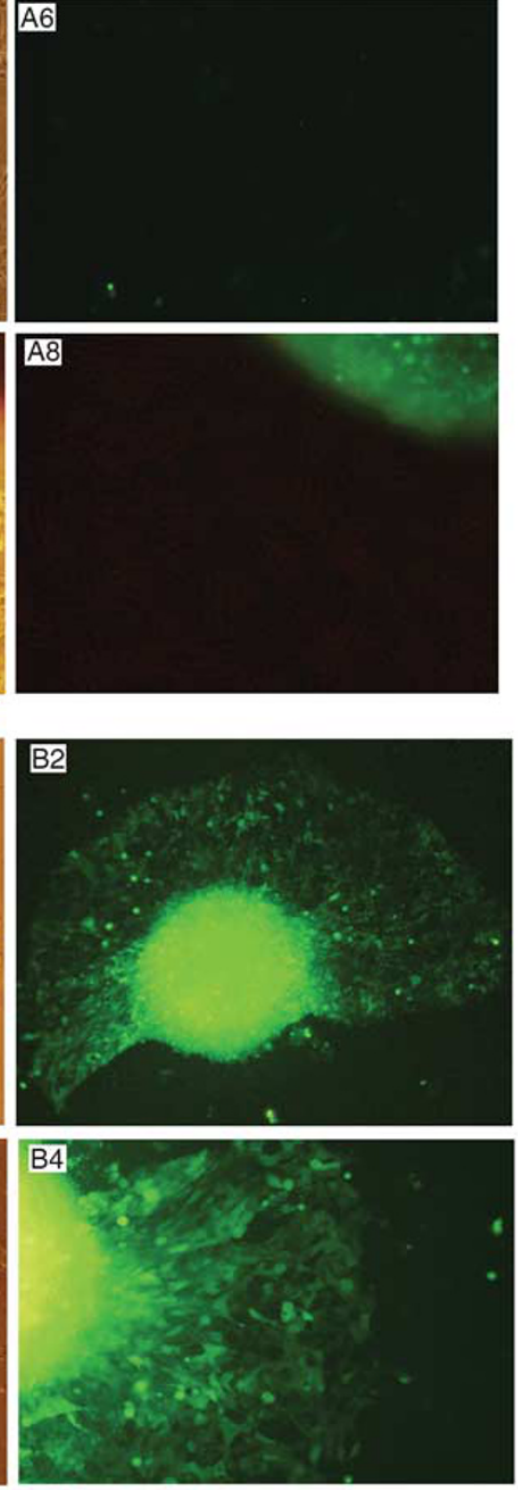
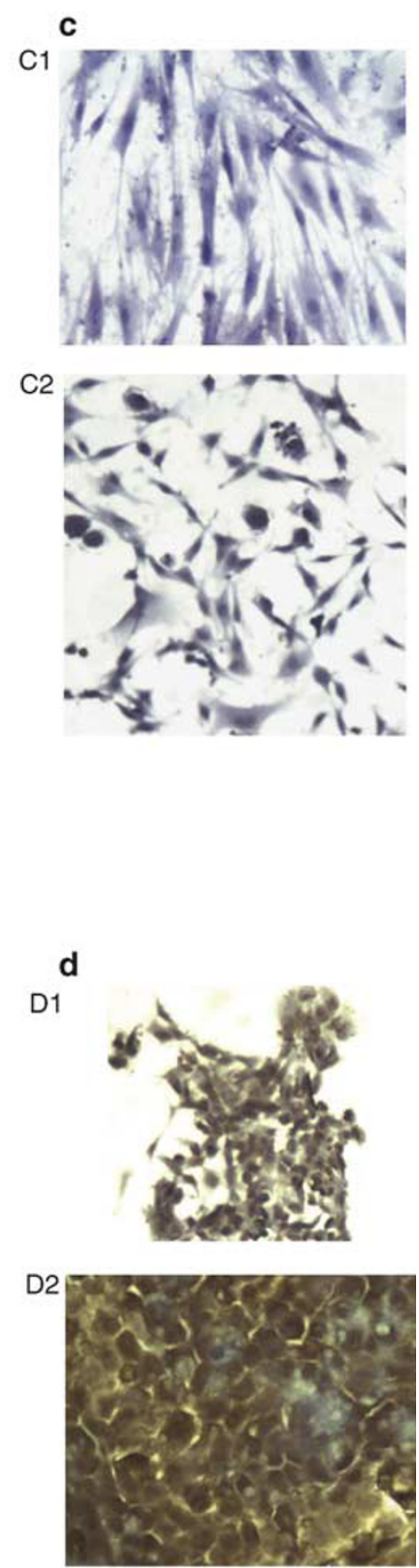
(Figure 10bC). The EGFP - cells were able to grow till becoming confluent and their daughter cells no longer showed EGFP signal. Whereas the cells cultured at high density did not show obvious decrease in the percentage of EGFP + cells within 20 passages. In subline isolation, for each well, $>50$ clones including EGFP + and EGFP - ones could be obtained. Species identification by multiplex PCR showed all the sublines were human-origin, and they were all 293-origin by E1A gene detection (Figure 9b and 9c). As only a very small fraction of non-human cells existed in the primary mixture cells and the mouse-species cells could only be subcultured for a limited passages ( $2-5$ passages), it could be also deduced that the EBV- cells that were capable of multiple passages were 293-origin. The EBV detection by ISH confirmed the observations that EGFP expression represented the existence of EBV genome in the cells (Figure 9d).

\section{DISCUSSION}

EBV is documented as the important etiologic agent of epithelial-origin cancer such as NPC. However, how the malignancy develops and how EBV acts in the pathogenesis are still unclear. ${ }^{1,10}$ It is essential to study the virus and its interaction with host cells in the context of the complete viral
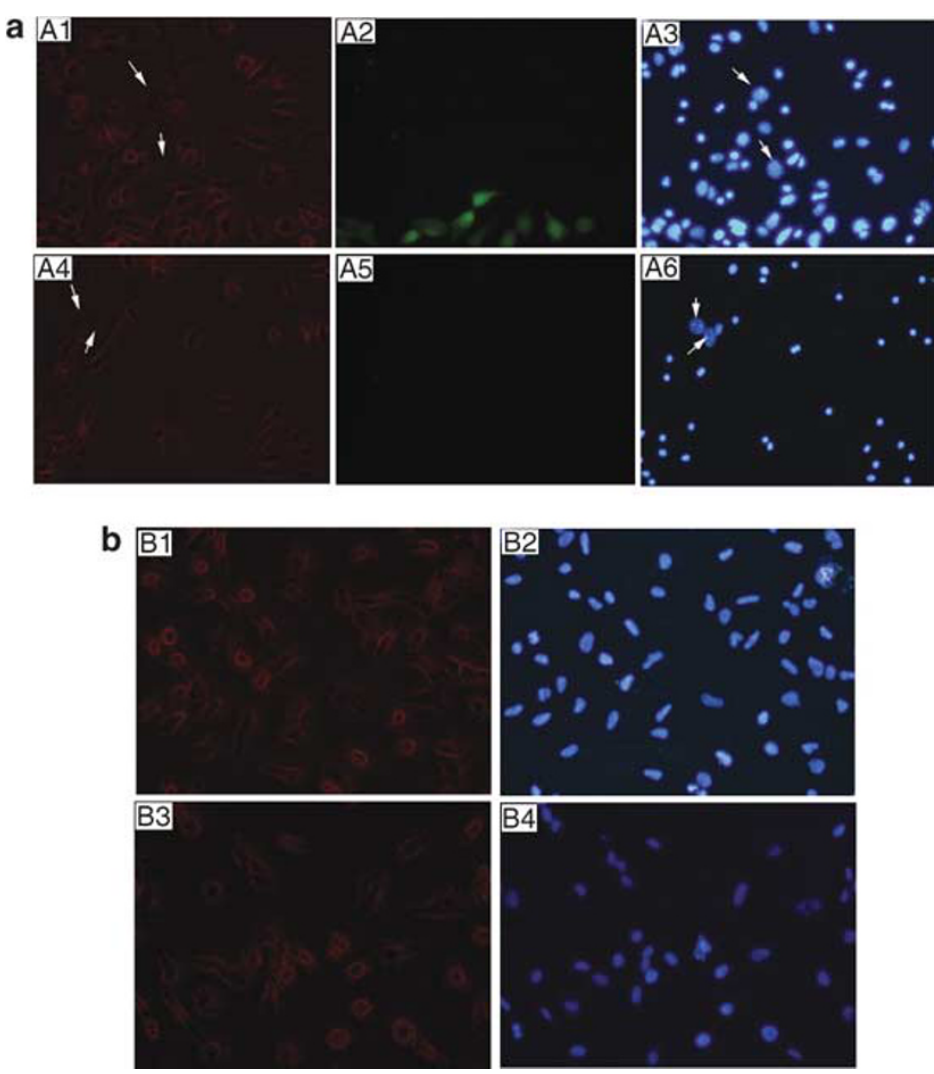
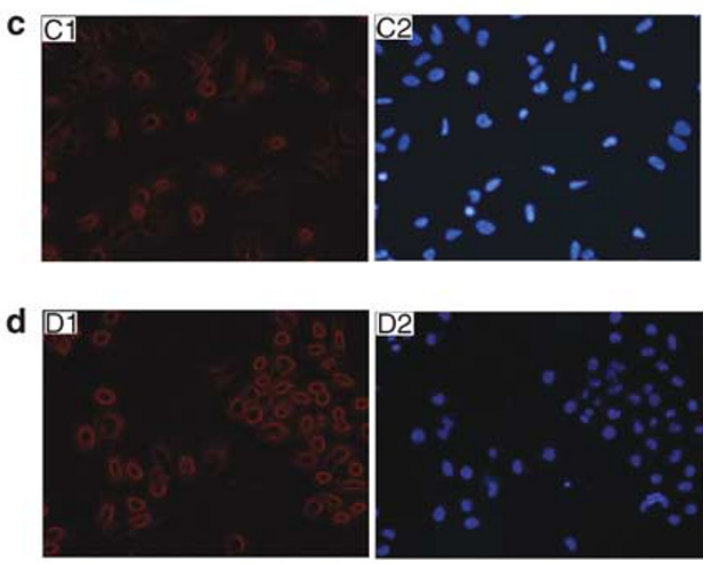

e
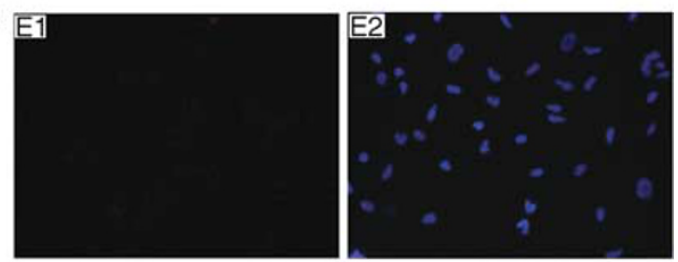

Figure 8 Immunofluorescence analysis of the expression of human epithelial cell protein, E-cadherin. (a) Primary culture of tumor tissue. The EGFP + and the outgrowth cells (EGFP-) were positive membrane staining and part of them with perinuclear staining (Rhodamine, red fluorescence). Several EGFPcells were negative staining as the arrows showed, with larger nucleus than that of the 293-origin cells. A2 or A5 showed the same fields as A1 or A4 under green fluorescence microscopy. For the GFP fluorescence (from EBV genome in the cells), the signal was weakened or even disappeared after the multiple experiment steps. (b) Tumor cells after digestion from primary culture (at passage 2). B1 and B3 were from two outgrowths. (c) The cell line 293. (d) An EBVcell line from nasopharyngeal carcinoma as a positive control. (e) The cell line NIH/3T3 (mouse embryonic fibroblast cell line) as a negative control. The panels $A 3, A 6, B 2, B 4, C 2, D 2$, and E2 showed the location of cell nucleus in the same fields as the left panels by staining with Hoechst. Original magnification: $\times 200$.

Figure 7 Maintenance or not of the EBV genome in the tumor cells during primary culture. (a) The cells were gradually released from the tumor pieces and some of them were able to grow at the out rim or in the vicinity of the tissue. All the new cells completely lost EGFP signal. Panels A2, A4, A6, and A8 were the result for EGFP expression observed at days 1, 5, 8, and 12, respectively, under an inverted fluorescence microscopy, and the left panels (A 1, A3, A5, A7) showed the phase contrast in the same fields as the right. (b) The primary and newly grown cells from those thin tissue pieces that directly adhered to the flask wall sustained EGFP. Cells in panels B1/B2 were grown at the same flask as those in panel (a). B1 or B3 showed the phase contrast of B2 or B4. (c) ISH detection showed all the cells around a thick tissue with EBER1-negative (blue). $\mathbf{C 1}$ and $\mathbf{C 2}$ showed different fields. (d) ISH detection showed all the clustered grown cells EBER1-positive (brown). D1 and D2 showed different fields. Original magnification: $\times 100($ A1-A8, B3, B4), $\times 40($ B1, B2), $\times 200$ (c and d). 

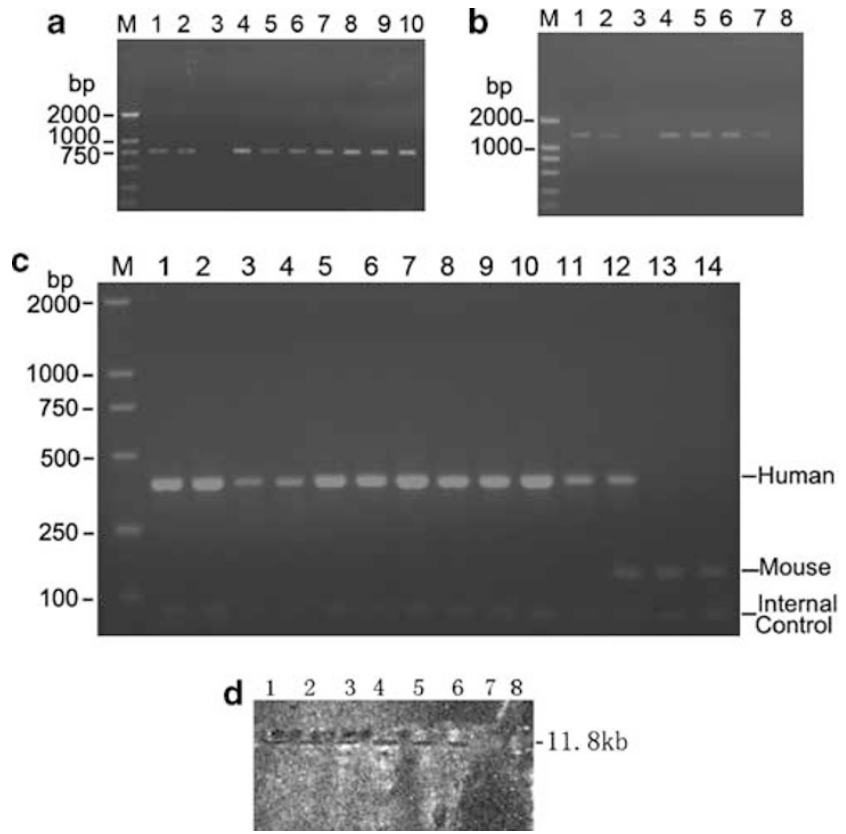

Figure 9 Cell species identification and EBV genome detection by PCR or Southern blot analysis. (a) Presence or not of Adenovirus E1A gene in the cells. M, DL2000 marker; lane 1, 293; 2, 293-EBV; 3, NIH/3T3 (mouse embryonic fibroblast cell line); 4, an EGFP + subline from the tumor cells; 5-10, six EGFP - sublines from the tumor cells. (b) Transcription or presence of the EBV-LMP1 gene in the tumor tissue or cells. M, DL2000 marker; 1, tumor tissue assayed by RT-PCR; $2-8$, detection from cell gDNA by PCR; 2 , 293-EBV; 3, 293; 4-7, four EGFP + sublines from the tumor cells; 8 , a mixture subline of 20 EGFP - clones from the tumor cells. For six EGFPsingle cell clones, no specific LMP1 fragments were amplified (image not shown here). (c) Human/mouse species identification of the cells by mutiplex PCR assay. M, DL2000 marker; 1, 293; 2, 293-EBV; 3, tumor cells at passage 2 from primary culture; 4, an EGFP + subline; 5, a mixture of 12 EGFP + subclones from the tumor cells; 6-10, five EGFP - sublines from the tumor cells; 11 , a mixture of 20 EGFP - clones from the tumor cells; 12 , a mixture of NIH/3T3 and an EGFP + clone (1:19); 13, NIH/3T3; 14, gDNA of nude mice spleen. (d) Identification of EBV BamHI-A fragment by Southern blot. 1, B95-8 cell line (as a positive control); 2, 293-EBV; 3, tumor cells at passage 3 from primary culture; 4 , a mixture of 12 EGFP + subclones from the tumor cells; 5 , a subline of an EGFP + clone; 6 , an EBV + cell line of nasopharyngeal carcinoma; 7, the cell line 293 (as a negative control); 8, a mixture of 5 EGFP- subclones from the tumor cells.

genome. The difficulty previously lied in several aspects of problem, including lack of suitable system for manipulating genes in the large EBV genome and establishing an EBVinfected malignant epithelial model. ${ }^{18,21}$ The establishment of infectious cloning technique based on bacterial artificial chromosomes has opened the way of genetic analysis of hepesviruses such as EBV. ${ }^{21,22,32}$ This technique also allows the viral genome to be transfected into cells directly without penetrating through the membrane receptor CD21, which is minimal on epithelial cells. ${ }^{11}$ By using this technique on the basis of the Maxi-EBV system, we established the EBV genome-infected cell line derived from human embryonic kidney epithelial cells (293). Because of the absence or minimal expression of CD21 molecule on epithelial 293 and NP69 cells, the virus produced from the 293-EBV cells failed to infect these epithelial cell lines directly.

To investigate the contributions of EBV to NPC development, especially the EBV activity in tumor development, the establishment of EBV induced or enhanced neoplastic transformation in human epithelial cells is critical. However, there has been no in vitro evidence that EBV infection directly induces tumor formation of epithelial cells in an animal model. It seems somewhat difficult for EBV-infection-only in normal or immortalized epithelial cells to trigger malignancy in a nude mice model. The cell line, 293, may exhibit tumorigenicity diversification in nude mice because of multiple passages. ${ }^{33}$ This property makes it possible for this cell line to be used as a model to express cancer-associated genes for the purpose of oncogenic potential or anti-tumor studies. ${ }^{34,35}$ In this study, EBV genome infection in EBV-negative 293 cells resulted in obvious increase of cell proliferation. In terms of the clonability and tumorigenicity, the results showed the transformation ability of the 293-EBV cell line was elevated significantly. The results also indicated that EBV enhanced the malignant potential of epithelial cells in a dose-dependent manner. To ensure that the resistance selection did not change the cellular biological properties, a hyg ${ }^{\mathrm{r}-}$ 293-cell line stably transfected with the plasmid pTRE2hyg (Clontech) was also established, and this cell line did not exhibit increased proliferation and tumorigenicity (data not shown). In the Maxi-EBV system, the EBV genome of $172 \mathrm{~kb}$ carries a mini-F factor and expression cassettes for EGFP and selection markers of about $10 \mathrm{~kb}$. From current reports on this similar system, ${ }^{13,36,37}$ there has been no evidence that the additional $10 \mathrm{~kb}$ of cassettes may bring impacts on the EBV genome function. In addition, other results in this study implied that EBV-encoded LMP1 was one of the important viral components responsible for the phenotype changes (see below). Therefore, it appeared unlikely that the increased malignant potential of the 293-EBV might be brought about by the adjunct. Nevertheless, this is to be verified in our further studies. This model provided data of EBV-enhanced proliferation and transformation both in vitro and in vivo. It could probably be exploited for further studies, including EBV gene function, anti-EBV therapy of tumor, and more EBV activities in tumor development.

The result showed that EBV genome latent infection activated NF- $\kappa$ B and JNK2 pathways (Figure 3). Both are involved in the main pathways activated by the oncoprotein, LMP1, and they are important for increased cell growth ability induced by LMP1. ${ }^{27,28}$ The alteration of these pathways and their cross-talk are involved in the disorder at G1/S check-point, ${ }^{38}$ resulting in the redistribution of cell cycle as our results showed (Figure 2d). Among the latent proteins of EBV, LMP1 is the only one that can transform non-lymphoid cells, such as fibroblasts. ${ }^{1,39}$ Our results suggested that LMP1 in the whole EBV genome was probably one of the important factors responsible for the enhancement of cell growth and tumorigenicity by the infection of the whole EBV genome. 
a
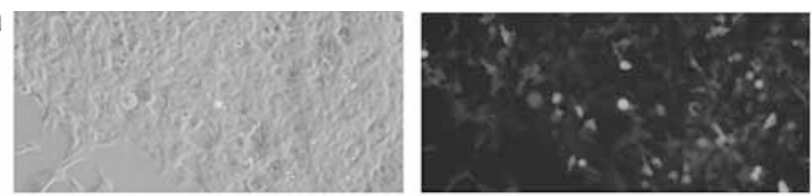

c
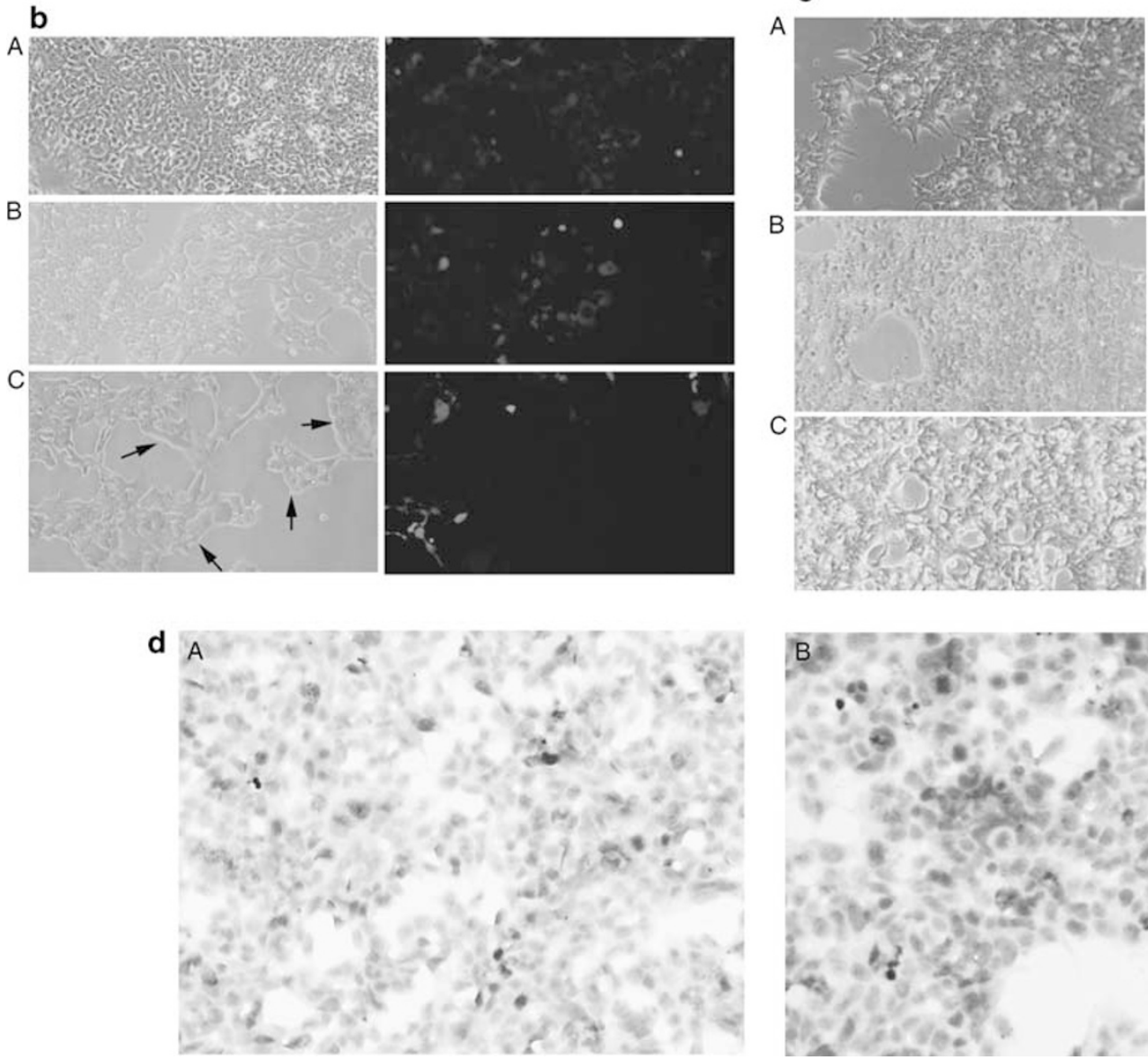
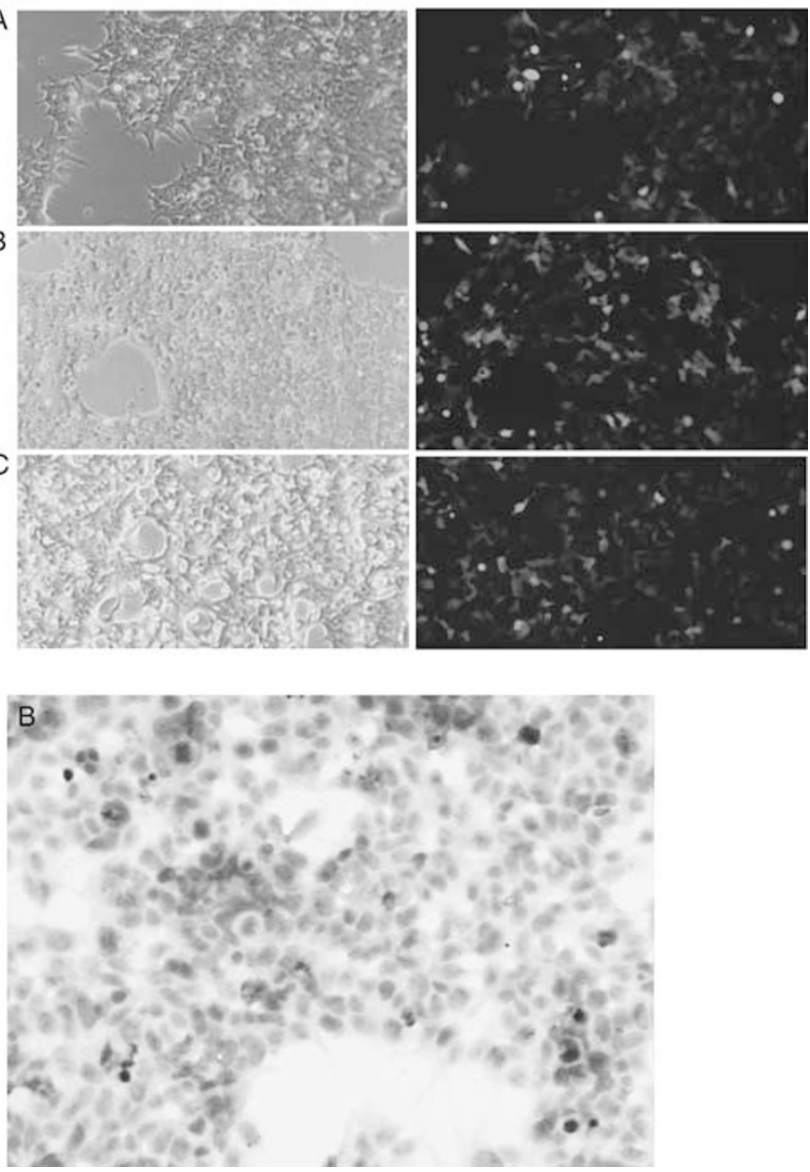

Figure 10 EBV maintenance or not in tumor cells at different density in subculture. (a) The second passage of the tumor cells. After 10 days in primary culture, the tissue and newly grown cells were trypsinized together (passage 1) for subculture. About $49 \%$ of the cells showed EGFP signal by cytometry flow detection. (b) From the third passage, the tumor cells were subcultured at low density (at 1:10 or 1:20 ratios). The result showed obvious decrease in the number of EGFP + cells after several passages. (A) The sixth passage (passage 3-6, 1:10 ratios). (B) The 11th passage (passage 3-11, 1:10 ratios). (C) The 14th passage (transferred at 1:20 ratio from the 13th passage) clustered cells lost EGFP signal (arrows), with 18\% of the cells showing EGFP signal by cytometry flow detection. (c) From the third passage, the tumor cells were subcultured at high density (1:2 ratios). There was no significant alteration in the number of EGFP + cells within 20 passages. (A) The sixth passage. (B) The 11 th passage. (C) The 20th passage, with $50 \%$ of the cells showing EGFP signal by cytometry flow detection. (d) ISH detection of EBER1 tallied the passage observations. (A) The 11th passage at low density. (B) The 15th at high density. $(\mathbf{a}-\mathbf{c})$ The left panels showed phase contrast in the same fields of the right panels. Original magnification: $\times 100(\mathbf{a}-\mathbf{c}), \times 200(\mathbf{d})$.

In the cellular gene expression, the c-Jun and c-Fos were downregulated. This was a conflict with some reports about LMP1 regulation, ${ }^{27,28}$ while was is in line with the report about LMP1 mutants. ${ }^{40}$ This inconsistence was possibly due to the use of different experimental system.

Serological studies on Burkitts's lymphoma and NPC have shown that elevated antibody titers against EBV lytic antigens may correlate with advanced cancer stages, poor prognoses, or poor tumor therapy. ${ }^{6,91,42}$ Some clues have indirectly indicated that EBV reactivation into lytic cycle may occur during tumor development. ${ }^{43,44}$ In our study, matured and budding virions were observed, directly confirming that EBV reactivation occurred spontaneously from latent genome to viral production in some cells at the site of tumor development.

The released virions might help the viral reinfection and effective persistence in peripheral circulation by B-cell survival mechanism. ${ }^{9}$ Several treatments have been reported to increase the proportion of EBV-infected B cells entering lytic cycle in vitro. ${ }^{45-47}$ The chemical, 12-O-tretradecanoylphorbol 
13-acetate, a known inducer of the EBV lytic cycle, is able to promote the transformation ability of EBV-infected non-tumorigenic 293 cells. ${ }^{15}$ Taken together with our results, it suggests that spontaneous entry into lytic cycle for EBVinfected cells with or without cofactors corresponds to low or high transformation potential of the cells. Therefore, it should be reiterated that EBV lytic cycle is an important stage, serving as a risk factor in cancer development.

In the Maxi-EBV system, the tagged fluorescence expression provided a convenient aid to observe the viral footprint. $^{21,22,37,48}$ As the results of tumor primary culture showed, EBV-infected cells with EGFP expression were EBV +. Detection of EBER1 by ISH (Figures 7 and 10), LMP1 by PCR (Figure 9b) or immunochemistry staining (data not shown), and other proteins such as EBNA1 ${ }^{48}$ confirmed the observation. The cells gradually released from the tumor tissues and the progeny cells no longer contained EBV genome. On the other hand, those daughter cells of the EBV-infected clustered cells (cultured under the same conditions in the same flask) retained the EBV genome efficiently. These two patterns implied that cell-to-cell contact was required for EBV's maintenance in the EBV + epithelial cells during expansion, and the result of the tumor cell subculture conformed to it. Cell-to-cell contact is also necessary for EBV infection from B lymphocyte to epithelial cells by the CD21-independent route. ${ }^{49}$

In NPC, EBV gene products can be detected frequently, ${ }^{6,7,17,44}$ and all the cells are EBV-positive in some biopsies. ${ }^{17,50}$ Detailed detections show that the cells in the periphery of the main tumor and all cells in the daughter nodules are easy to be found EBV-positive. ${ }^{51}$ The monoclonality of the viral DNA also indicates that the malignancy has arisen from clonal expansion of EBV-infected progenitor cell(s). ${ }^{50,52}$ Thus, it seems that EBV-infected cells are also tufted in NPC tumor tissues, and the mechanism of cell-tocell contact might help us to understand the virus infection and clonal expansion in EBV's association with NPC. It is commonly observed and of interest that EBV-infected NPC or epithelial cells gradually lose EBV genome during passages in vitro. ${ }^{14,51,53}$ Our findings showed that EBV lost from the cells owing to the loss of cell-to-cell contact mechanism when subcultured at low density. Once they lost cell-to-cell contact, the EBV genome could be eliminated from the cell, yet the EBV-negative cell had the ability of proliferation. The cells usually retained the EBV genome efficiently at high density (Figure 8c). However, it is mentionable that under some conditions such as poor cryopresevation, the cell survival rate of resuscitation may become too low, and the low cell density would still lead to easy loss of EBV genome (data not shown). It has been shown that the loss of EBV from NPC cells leads to the loss or reduction of tumorigenicity, and the reintroduction of EBV enhances the tumorigenicity. ${ }^{51}$ The observation indicates that the maintenance of EBV is important for the oncogenic activity of the infected cells. On the other hand, EBV might be driven away easily from the host cells. This state of affairs reflects the interaction between the virus and the host cell.

\section{ACKNOWLEDGEMENTS}

We thank Professor Dr Wolfgang Hammerschmidt (Department of Gene Vectors, GSF-National Research Center for Environment and Health, Germany) for providing the Maxi-EBV system (p2089) and valuable communication in the work. We are grateful to Professor James McCarthy and Dr Jianbo Yang (Tumor Biology and Progression Program in Masonic Cancer Center, University of Minnesota), Dr Yi Li and Dr Shixia Huang (Department of Molecular and Cellular Biology, Baylor College of Medicine) for sharing ideas and making suggestions. We also thank Mrs Sheng (Animal Center, Central South University) for the kind help in breeding the mice. This work was supported by the National Key Project of Scientific Research Programs (2006CB910502, 2006CB910504) and the 111 Project (111-2-12).

\section{DISCLOSURE/CONFLICT OF INTEREST}

The authors declare no conflict of interest.

1. Bornkamm GW, Hammerschmidt W. Molecular virology of Epstein-Barr virus. Philos Trans R Soc Lond B Biol Sci 2001;356:437-459.

2. zur Hausen $H$, Schulte-Holthausen $H$, Klein $G$, et al. EBV DNA in biopsies of Burkitt tumours and anaplastic carcinomas of the nasopharynx. Nature 1970;228:1056-1058.

3. Raab-Traub N, Flynn K, Pearson G, et al. The differentiated form of nasopharyngeal carcinoma contains Epstein-Barr virus DNA. Int J Cancer 1987;39:25-29.

4. Robertson ES. Epstein-Barr Virus. Caister Academic Press: Wymondham, England, 2005.

5. Metzenberg S. Levels of Epstein-Barr virus DNA in lymphoblastoid cell lines are correlated with frequencies of spontaneous lytic growth but not with levels of expression of EBNA-1, EBNA-2, or latent membrane protein. J Virol 1990;64:437-444.

6. Young LS, Rickinson AB. Epstein-Barr virus: 40 years on. Nat Rev Cancer 2004;4:757-768.

7. Young LS, Murray PG. Epstein-Barr virus and oncogenesis: from latent genes to tumours. Oncogene 2003;22:5108-5121.

8. Li HP, Chang YS. Epstein-Barr virus latent membrane protein 1: structure and functions. J Biomed Sci 2003;10:490-504.

9. Macsween KF, Crawford DH. Epstein-Barr virus-recent advances. Lancet Infect Dis 2003;3:131-140.

10. Rickinson A. Concluding overview: looking back, looking forward. Philos Trans R Soc Lond B Biol Sci 2001;356:595-604.

11. Li QX, Young LS, Niedobitek G, et al. Epstein-Barr virus infection and replication in a human epithelial cell system. Nature 1992; 356:347-350.

12. Lo KW, To KF, Huang DP. Focus on nasopharyngeal carcinoma. Cancer Cell 2004;5:423-428.

13. Lo AKF, Lo KW, Tsao SW, et al. Epstein-Barr virus infection alters cellular signal cascades in human nasopharyngeal epithelial cells. Neoplasia 2006;8:173-180.

14. Danve $C$, Decaussin G, Busson P, et al. Growth transformation of primary epithelial cells with a NPC-derived Epstein-Barr Virus strain. Virology 2001;288:223-235.

15. Li BM, Ji ZW, Liu ZS, et al. Epstein-Barr virus in synergy with tumorpromoter-induced malignant transformation of immortalized human epithelial cells. J Cancer Res Clin Oncol 1997;123:441-446.

16. Sam CK, Brooks LA, Niedobitek G, et al. Analysis of Epstein-Barr virus infection in nasopharyngeal biopsies from a group at high risk of nasopharyngeal carcinoma. Int J Cancer 1993;53:957-962.

17. Zeng ZY, Zhou YH, Zhang WL, et al. Gene expression profiling of nasopharyngeal carcinoma reveals the abnormally regulated Wnt signaling pathway. Hum Pathol 2007;38:120-133.

18. Raab-Traub N. Epstein-Barr virus in the pathogenesis of NPC. Semin Cancer Biol 2002;12:431-441.

19. Guasparri I, Bubman D, Cesarman E. EBV LMP2A affects LMP1mediated NF- \\{kappa\\}B signal. Blood 2008;111:3813-3820.

20. Sheng $W$, Decaussin $G$, Ligout $A$, et al. Malignant transformation of Epstein-Barr virus-negative akata cells by introduction of the BARF1 gene carried by Epstein-Barr virus. J Virol 2003;77:3859-3865. 
21. Delecluse HJ, Hammerschmidt W. The genetic approach to the Epstein-Barr virus: from basic virology to gene therapy. J Clin Pathol Mol Pathol 2000;53:270-279.

22. Delecluse HJ, Hilsendegen T, Pich D, et al. Propagation and recovery of intact, infectious Epstein-Barr virus from prokaryotic to human cells. Proc Natl Acad Sci USA 1998;95:8245-8250.

23. Fingeroth JD, Weis JJ, Tedder TF, et al. Epstein-Barr virus receptor of human B lymphocytes in the C3d receptor CR2. Proc Natl Acad Sci USA 1984;81:4510-4514.

24. Tang $\mathrm{YL}, \mathrm{Lu} \mathrm{JH}, \mathrm{Wu} \mathrm{MH}$, et al. Lytic replication and inductive production of recombinant Epstein-Barr virus visualized. Prog Biochem Biophys 2007;34:418-424.

25. Tsao SW, Wang X, Liu Y, et al. Establishment of two immortalized nasopharyngeal epithelial cell lines using SV40 large T and HPV16E6/E7 viral oncogenes. Biochim Biophys Acta 2002;1590: $150-158$.

26. Cooper JK, Sykes G, King S, et al. Species identification in cell culture: a two-pronged molecular approach. In Vitro Cell Dev Biol-Animal 2007;43:344-351.

27. He $Z$, Xin $B$, Yang $X$, et al. Nuclear factor- $\kappa B$ activation is involved in LMP1-mediated transformation and tumorigenesis of rat-1 fibroblasts. Cancer Res 2000;60:1845-1848.

28. Kieser A, Kilger E, Gires O, et al. Epstein-Barr virus latent membrane protein 1 triggers AP-1 activity via the c-Jun N-terminal kinase cascade. EMBO J 1997;16:6478-6485.

29. Sylla BS, Hung SC, Davidson DM, et al. Epstein-Barr virus-transforming protein latent infection membrane protein 1 activates transcription factor NF-kappaB through a pathway that includes the NF-kappaBinducing kinase and the IkappaB kinases IKKalpha and IKKbeta. Proc Natl Acad Sci USA 1998;95:10106-10111.

30. Angel P, Karin M. The role of Jun, Fos, and the AP-1 complex in cell proliferation and transformation. Biochem Biophys Acta 1991;1072:129-157.

31. Pulverer BJ, Kyriakis JM, Avruch J, et al. Phosphorylation of c-Jun mediated by MAP kinases. Nature 1991;353:670-674.

32. Wagner M, Ruzsics Z, Koszinowski UH. Herpesvirus genetics has come of age. Trends Microbiol 2002;10:318-324.

33. Shen C, Gu M, Song C, et al. The tumorigenicity diversification in human embryonic kidney 293 cell line cultured in vitro. Biologicals 2008;36:263-268.

34. Moore M, Horikoshi N, Shenk T. Oncogenic potential of the adenovirus E4orf6 protein. Proc Natl Acad Sci USA 1996;93:11295-11301.

35. Guan LS, Li GC, Liu LQ, et al. Rb-associated protein 46 (RbAp46) suppresses the tumorigenicity of adenovirus-transformed human embryonic kidney 293 cells. Int J Cancer 2001;93:333-338.

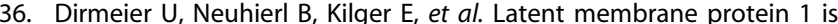
critical for efficient growth transformation of human $B$ cells by EpsteinBarr virus. Cancer Res 2003;63:2982-2989.

37. Feederle R, Neuhierl B, Bannert H, et al. Epstein-Barr virus B95.8 produced in 293 cells shows marked tropism for differentiated primary epithelial cells and reveals interindividual variation in susceptibility to viral infection. Int J Cancer 2007;121:588-594.

38. Kaltschmidt B, Kaltschmidt C, Hehner SP, et al. Repression of NFkappaB impairs HeLa cell proliferation by functional interference with cell cycle checkpoint regulators. Oncogene 1999;18:3213-3225.

39. Wang D, Liebowitz D, Kieff E. An EBV membrane protein expressed in immortalized lymphocytes transforms established rodent cells. Cell 1985;43:831-840.

40. Larcher C, Bernhard D, Schaadt E, et al. Functional analysis of the mutated Epstein-Barr virus oncoprotein LMP1(69del): implications for a new role of naturally occurring LMP1 variants. Haematologica 2003;88:1324-1335.

41. Desgranges C, Bornkamm GW, Zeng Y, et al. Detection of Epstein-Barr viral DNA internal repeats in the nasopharyngeal mucosa of Chinese with IgA/EBV-specific antibodies. Int J Cancer 1982;29:87-91.

42. Gu AD, Xie YB, Mo HY, et al. Antibodies against Epstein-Barr virus gp78 antigen: a novel marker for serological diagnosis of nasopharyngeal carcinoma detected by xMAP technology. J Gen Virol 2008;89: 1152-1158.

43. Trumper PA, Epstein MA, Giovanella BC, et al. Isolation of infectious EB virus from the epithelial tumor cells of nasopharyngeal carcinoma. Int J Cancer 1977;20:655-662.

44. Meisler Al, Schuster V, Pukrop T, et al. Epstein-Barr virus and nasopharyngeal cancer. N Engl J Med 1996;334:122-123.

45. Luka J, Kallin B, Klein G. Induction of the Epstein-Barr virus (EBV) lytic cycle in latently infected cells by $n$-butyrate. Virology 1979;94:228-231.

46. Takada K, Ono Y. Synchronous and sequential activation of latently infected Epstein-Barr virus genomes. J Virol 1989;63:445-449.

47. Tovey MG, Lenoir G, Begon-Lours J. Activation of latent Epstein-Barr virus by antibody to human IgM. Nature 1978;276:270-272.

48. Shannon-Lowe CD, Neuhierl B, Baldwin G, et al. Resting B cells as a transfer vehicle for Epstein-Barr virus infection of epithelial cells. Proc Natl Acad Sci USA 2006;103:7065-7070.

49. Chang $\mathrm{Y}$, Tung $\mathrm{CH}$, Huang $\mathrm{YT}$, et al. Requirement for cell-to-cell contact in Epstein-Barr virus infection of nasopharyngeal carcinoma cells and keratinocytes. J Virol 1999;73:8857-8866.

50. Pathmanathan R, Prasad U, Sadler R, et al. Clonal proliferations of cells infected with Epstein-Barr Virus in preinvasive lesions related to nasopharyngeal carcinoma. N Engl J Med 1995;333:693-698.

51. Teramoto N, Maeda A, Kobayashi K, et al. Epstein-Barr virus infection to Epstein-Barr virus-negative nasopharyngeal carcinoma cell line TW03 enhances its tumorigenicity. Lab Invest 2000;80:303-312.

52. Raab-Traub N, Flynn K. The structure of the termini of the Epstein-Barr virus as a marker of clonal cellular proliferation. Cell 1986:47:883-889.

53. Glaser R, Zhang HY, Yao KT, et al. Two epithelial tumor cell lines (HNE-1 and HONE-1) latently infected with Epstein-Barr virus that were derived from nasopharyngeal carcinomas. Proc Natl Acad Sci USA 1989;86:9524-9528. 